\title{
Initial Social Network Analysis of Producers Working Towards Sustainability Suggests Weak Ties and Potential Fragmentation
}

\author{
K. Stofer ${ }^{1}$, J. Fulton ${ }^{2}$, H. Nesbitt ${ }^{3}$, A. Prizzia ${ }^{4}$, K. Garrett ${ }^{5}$, J. Rosario 6
}

\begin{abstract}
For farmers to adopt and maintain sustainable farming practices, they must have the resources and network to succeed with this work and must realize a positive impact on their business model. As a food system is ultimately made up of the people, organizations, and institutions that grow, move, buy and sell food, we must understand who is at the center of this network, who is well-connected, and who is peripheral. Within a particular regional food system in a highly productive southeastern U.S. state, the network of local producers interested in sustainable production, including environmental and economic components, seems to be growing. However, it is unclear who benefits from this system and whether this system is growing in a way that encourages and enhances the benefits for sustainable agriculture. Existing evidence for the network size and its vulnerabilities has been anecdotal, from Extension agents and their contacts with individual producers, rather than based on systematic research. We used social network analysis to understand the status of the system and its constituents. Connections between producers appear to be weak overall with potential fragmentation, suggesting a fragility that could easily derail efforts to increase sustainable production in the region.
\end{abstract}

\section{Keywords}

regional food system, sustainable agriculture, sustainable production, resource sharing

1. Kathryn Stofer, Research Associate Professor, STEM Education and Outreach, University of Florida, PO Box 110540 University of Florida, Gainesville, FL 32611, stofer@ufl.edu, (D) https://orcid.org/0000-0002-3659-490X

2. James C. Fulton, Graduate Research Assistant, University of Florida, pcvgt@ufl.edu

3. Heather R. Nesbitt, Graduate Research Assistant, University of Florida, PO Box 110540 University of Florida, Gainesville, FL 32611, Heather.nesbitt@ufl.edu, (iD) https://orcid.org/0000-0001-5339-8516

4. Anna Prizzia, Academic Program Specialist; Program Director and Campus Food Systems Coordinator, University of Florida, aprizzia@ufl.edu, (D) https://orcid.org/0000-0002-3028-4062

5. Karen A. Garrett, Preeminent Professor, University of Florida, karengarrett@ufl.edu, (iD) https://orcid.org/0000-0002-6578-1616

6. Jhon Jarome Rosario, Undergraduate Research Assistant, University of Florida, jhonrosario@ufl.edu, 


\section{Introduction and Problem Statement}

Sustainable agriculture (Gold, 2012) is key to feeding the $21^{\text {st }}$ century's growing population. Sustainability on a regional scale in turn is vital to global efforts. For producers to adopt and maintain sustainable practices, they must have necessary resources and realize a positive impact on their business model (Sustainable Agriculture Research \& Education, 2010). Sustainable agriculture cannot move forward if the people in a regional food system, especially producers, are not talking to each other, working together, and sharing resources.

Within a regional food system in a highly productive southeastern U.S. state, the network of producers interested in sustainable production seems to be growing. Sustainability is of particular importance to diversifying agricultural and rural communities who have a growing interest in local food (Gorham et al., 2015) and direct market channels. In our region, most producers still sell through brokers and focus on national and multi-national markets. Despite a trend toward larger farms, in our state, $90 \%$ of farms are considered small, with up to $\$ 250,000$ in annual sales (Small Farms and Alternative Enterprises, n.d.).

At the same time, consumer demand for local food is increasing (Giovannucci et al., 2010), though definitions of local may vary and include regional and state areas (Adams \& Salois, 2010; Aprile et al., 2016; Giovannucci et al., 2010; Martinez, 2010). Direct to consumer sales and marketing primarily happens from smaller operations; demand for these buying options is also increasing as consumers seek to support producers close to home (Martinez, 2010). However, small local producers face challenges to supplying local markets, some of which can be overcome by pooling resources (Martinez, 2010) through cooperation in a regional network. Therefore, we must understand the current status of the system of available and well-used human and organizational resources to frame future support and research for our regional network.

\section{Theoretical and Conceptual Framework}

Previous evidence for the size and strength of the network has been anecdotal from Extension agents rather than based on systematic research. To provide effective and efficient clientele programs, we must understand who is well-connected, what producers ask of others in the network, and who may not be in the network (Doerfert, 2011). Therefore, we used social network analysis (Christensen \& O'Sullivan, 2015; Scott \& Carrington, 2011) as a framework as part of a larger study to support flow of sustainable agricultural practices throughout our producer network of Extension clientele (Kumar Chaudhary \& Warner, 2015). This study represents the first step in gathering information about central players in the network through focus groups in order to perform a full social network analysis (Zack, 2000). Ultimately we want to promote diffusion of sustainable agricultural practices throughout the network (Rogers, 2003). 
Developing land for human habitation reduces land for production (Lubell et al., 2014). The pressures of increased yield per acre may lead to environmental degradation, countering efforts to continue land's productivity (Cassman, 1999; Tilman et al., 2002, 2011). Smaller producers in particular struggle against shrinking profit margins (Bunge, 2017; United States Department of Agriculture Economic Research Service, 2018), making costly improvements and investments in measures to move toward environmental sustainability or income diversification (Meert et al., 2005) more and more precarious if not altogether out of reach.

Food systems are social structures comprised of a connected network of people, such as producers and organizations (Brass et al., 2004). Producers are one part of the larger U.S. and global food system. We use the food system definition of Goetz (2016), "the networked set of input suppliers, farmers, processors, distributors, and consumers" (p. 420), although for the purposes of this paper we ignore the rules that make the system work. Producers in previous modern food systems models (1986) only interact with processors, and consumers buy only from food service firms or grocery retailers and wholesalers (Goetz, 2016). Today, that model is more complicated. Examining regional networks for their self-reliance and ability to provide for their local residents has become paramount as production has also become increasingly geographically concentrated (Griffin et al., 2015). Social network analysis has shown how networks promote sustainability in regional agroecological systems by supporting social ties and allowing for diffusion of innovations (Levy \& Lubell, 2018; Lubell et al., 2014). Previous social network analysis for agricultural groups has often focused on a single crop (Levy \& Lubell, 2018). Egocentric network analysis in particular can be used to study diffusion of information as well as identify the most important sources of information (Haythornthwaite, 1996).

When we know the structure of a communication network, we can consider implications of structure for outcomes such as sustainability. We can identify which nodes may play particularly important roles in the system. When there are problems, such as the need for sustainable disease management, specific nodes may be key to sampling and mitigation because of their role in communication networks and/or their role in epidemic networks (Andersen et al., 2019; Buddenhagen et al., 2017). Particular knowledge brokers may play key roles within networks (Cvitanovic et al., 2017) and in linking networks to other aspects of the environment (Klerkx et al., 2010). People with strong network links for access to information have been associated with transformational change (Dowd et al., 2014). In the context of improving the well-being of agricultural regions, understanding which people are not well served by networks of communication or technology spread can support the design of better systems (Garrett et al., 2018; Henry \& Vollan, 2014). Network structure may determine whether producers are exposed needed information (Xu et al., 2018) and convinced to make changes to practices.

\section{Purpose}

The first objective of this study was to describe the network of self-selected sustainable or emerging sustainable producers in the region to determine a baseline for strengthening the 
network. Our second objective was to determine how often producers sought particular assistance on sustainability and from whom. Therefore, we had the following research questions:

1. What are the self-identified characteristics of producers and sustainable and emerging sustainable operations in the region?

2. What are the current number and strengths of relationships in the region among selfreported sustainable or emerging sustainable producers and supporting organizations?

3. What is the relationship of self-reported level of sustainability and network centrality?

\section{Methods}

We defined our regional network as encompassing 17 counties in the northeastern portion of an agriculturally intensive U.S. state. The region included one major metropolitan area and one regional metropolitan area, home to a land-grant university. Each county in the region has a staffed Extension office associated with the university. We recruited survey participants from those counties through Extension agents identified by Prizzia, who is both a program director in the university's college of agriculture as well as a community activist in local food systems. We asked those key Extension figures to distribute the survey to their local producer contacts. Additionally, we emailed a recruitment list developed in a related study of sustainable producers in the region (Stofer et. al., 2021) and collected emails from producers at local farmer's markets in early 2016. We encouraged all participants to share the survey with other producers not on the direct email lists to use snowball sampling. We limited participation to people at least 18 and offered a nominal monetary incentive to every $25^{\text {th }}$ survey participant.

We asked two focus groups of purposively recruited sustainable producers in two metropolitan areas in our region to identify the key contacts on sustainable production in our region (Stofer et. al., 2021). The survey for all aspiring or sustainable producers in the region asked about which human or organizational resources in the network they use and with whom they collaborate most often (Scott \& Carrington, 2011; Zack, 2000). We listed personnel identified as key contacts by the focus group participants as explicit choices for contact in the survey. In addition, participants could write-in other contacts they consulted about sustainable production within the last two years. After identifying individuals with whom they had contact, we asked participants to indicate which county offices of Extension and any other outside groups they had contacted about sustainability in the past two years. For each contact indicated, we asked participants about the topic and frequency of the consultation(s): frequently (multiple times monthly), semi-frequently (multiple times annually) or emergency only (once or twice annually).

We also asked for basic demographic information; self-identified level of production from considering sustainability, to partly sustainable, to almost totally sustainable; county or counties of operation and products sales; approximate annual gross sales; how their operation sells; the type of products their operation sells; and how long their operation has been in the 
region. See Supplemental Material at https://bit.ly/3q4pSNm for full survey questions and choices.

We hosted the survey in Qualtrics and sent invitations via three emails in Summer 2016, one initial email and two reminder emails (Dillman et al., 2009). We checked data points and included respondents who gave consent and provided a name. In some cases, when we asked about the level of communication with another person or organization, the respondent failed to list a communication frequency. In those cases, we imputed the frequency as emergency. While we knew some individuals were representatives of listed organizations, such as an Extension agent for a particular county, if respondents listed both the individual Extension agent and the county Extension office as separate contacts, then we maintained those ratings separately. If the county extension office was not listed but an individual Extension agent from that county had been, then we added the county extension office and gave it a frequency rating of emergency for those topics selected for the individual agent. We converted communication frequencies into numerical values, summed them, and aggregated them by topics of communication (e.g. animals, cultivation, tools). Fulton organized and imported survey data into the R programming environment and used igraph, maps, and dplyr packages for network structure analysis and scoring. We used ordinal logistic regression to analyze relationships between network centrality measures and self-reported sustainability levels, using MASS, ordinal, and erer $\mathrm{R}$ packages. ${ }^{1}$

\section{Findings}

\section{Research Question 1 - Participant and Operation Characteristics}

There were 41 complete and usable survey responses, including four duplicates. Stofer reviewed the duplicated entries and found most were exact copies of the original responses. We collated cases where respondents provided additional information in a duplicate. No instances resulted in any conflicting information between original and subsequent responses. One additional respondent completed the information about their production and sales types and locations but neither communication partners nor individual demographics; we retained this participant in the network as an isolate. Therefore, we had a final total of 38 respondents. Our estimated response rate based on available data ranges from 4-100\% (See Supplemental Material at https://bit.ly/3q4pSNm for response rate calculation). Prizzia's involvement in the network leads her to believe our respondents were representative of the network at that time.

Respondents varied in their age, ranging from 25-74; ethnicity, though most were White; and level of education, though most had either a bachelor's or master's degree, as shown in Table 1. Thirty-one respondents were owner/operators, eight were managers, and two were employees, including two respondents who indicated they fulfilled all three roles.

\footnotetext{
${ }^{1} \mathrm{R}$ packages are available at: $\underline{\text { https://iviagraph.org/r/, }}$
} 
Table 1

Survey Respondent Demographics

\begin{tabular}{|c|c|c|c|c|c|}
\hline Age & Total & Race/Ethnicity & Total & Level of education & Total \\
\hline $18-24$ & 0 & Asian/Pacific Islander & 1 & $\begin{array}{l}\text { High school graduate, } \\
\text { diploma or } \\
\text { equivalent }\end{array}$ & 3 \\
\hline $25-34$ & 5 & Black/African American & 1 & $\begin{array}{l}\text { Some college credit, } \\
\text { no degree }\end{array}$ & 5 \\
\hline $35-44$ & 6 & $\begin{array}{l}\text { Native American/ } \\
\text { American Indian }\end{array}$ & 0 & $\begin{array}{l}\text { Trade/technical/ } \\
\text { vocational training }\end{array}$ & 2 \\
\hline $45-54$ & 6 & Hispanic/ Latino & 2 & Associate's degree & 3 \\
\hline $55-64$ & 15 & White & 28 & Bachelor's degree & 9 \\
\hline $65-74$ & 5 & Other & 1 & Master's degree & 13 \\
\hline 75 or older & 0 & Multi-ethnic & 1 & $\begin{array}{l}\text { Doctorate/ } \\
\text { professional degree }\end{array}$ & 2 \\
\hline No response & 1 & $\begin{array}{l}\text { White-Hispanic } \\
\text { No response }\end{array}$ & $\begin{array}{l}1 \\
3\end{array}$ & No response & 1 \\
\hline
\end{tabular}

\section{Production Demographics}

In their self-assessment, 15 participants listed their farms as having "at least some" production currently sustainable and 18 as having "virtually all" production sustainable. One respondent was in the process of becoming sustainable and two were considering sustainability, with one final participant not answering this question. However, some participants in each of these levels of sustainability were disconnected from other participants in the network, meaning that they did not list any contacts within the past two years related to sustainability. We had 11 isolates in the network who did not list any contacts; we discuss their role in the analysis further below. Seven isolates reported that their production was virtually all sustainable, three listed their production as at least somewhat sustainable, and one reported they were in the process of becoming sustainable. The final participant who did not list a level for the sustainability of their production also was an isolate. However, all these participants did complete demographics at the very end of the survey, suggesting they deliberately skipped these questions rather than exiting the survey without completing it.

Most respondents reported under $\$ 250,000$ gross annual sales ${ }^{2}$, with only two reporting $\$ 250,000-\$ 500,000$ and four reporting more than $\$ 500,000$ annual gross. All but six reported selling at least some directly to consumers, and fourteen report selling at least some to wholesalers. Other ways producers sell their products include to restaurants, as on-site edible landscaping, through community-supported agriculture (CSA), via livestock markets, to other farmers, and through buying clubs.

\footnotetext{
${ }^{2}$ We defined sales categories deliberately broadly to preserve participant anonymity and encourage participation based on our knowledge of the producers in the region to categorize productions as small, medium, and large.
} 
The vast majority of growers reported their operation base as located in either one of two North-Central Florida counties which contained the major metropolitan areas. Respondents also stated that the majority of their sales occurred in either of these two counties with limited sales in other counties throughout the state (Figure 1).

\section{Figure 1}

County of Production and Sales Locations Listed by Respondents
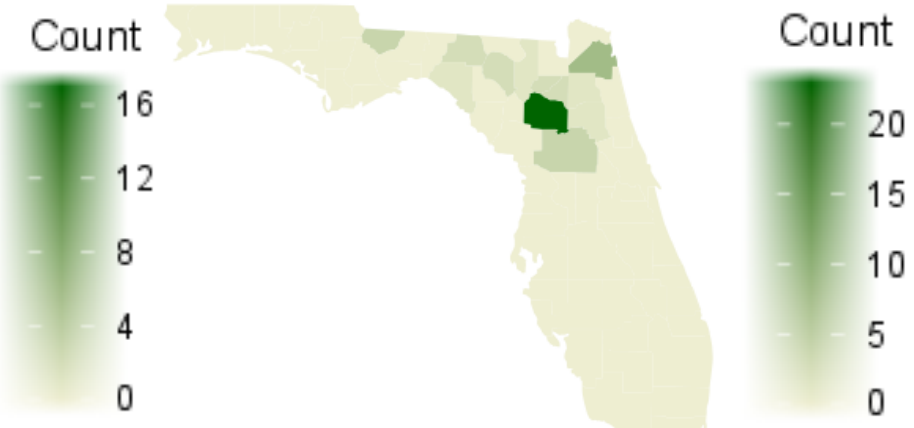

Note. The county reported with the highest number of locations for both production (left) and sales (right) was Alachua county ( $n=17$ and 23 , respectively).

\section{Research Questions 2 and 3 - Network Characterization}

Four groups comprise the overall network: producers, Extension, outside organizations, and non-producers. The summed communication frequencies and aggregated communication topics provide the network's general model of communication among actors (See Figure 2).

\section{Figure 2}

Summed Network Diagram of Communication Among Actors

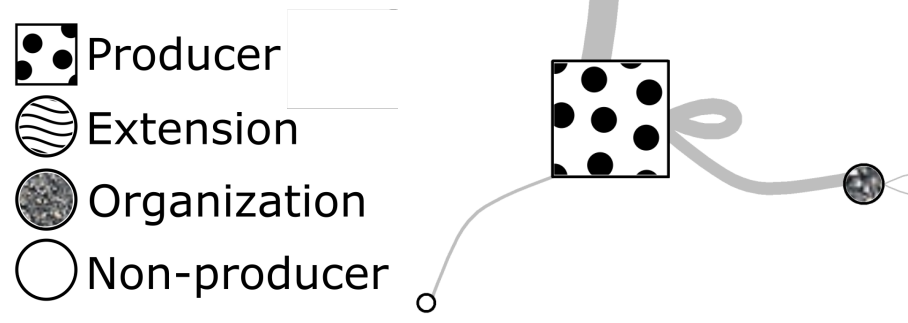

Note. Shape size depicts number of actors per group. Line width indicates number of contacts. 
Most of the identified network was of either producers or Extension entities, including both Extension offices (counties) and individual Extension agents named. Participants reported the largest number of communication links between Extension and producers. Producers also reported relationships with the three other groups, and each group except non-producers reported relationships within their own group, shown as self-loops in Figure 2. Table 2 shows network centrality indicators per group. Given the ego-centric nature, producers were the center of the network with the highest centrality indicators, and the other groups had low levels of centrality. People who acted as bridges were primarily individual producers. In the disaggregated network, it was apparent that there was significant network structure, with most producers connected to other individuals/entities. However, several producers were apparently isolated (see Figure 3). Approximately five percent of the total number of possible links between entities were present in the complete network (see Figure 4).

\section{Figure 3}

Complete Disaggregated Network with Isolates
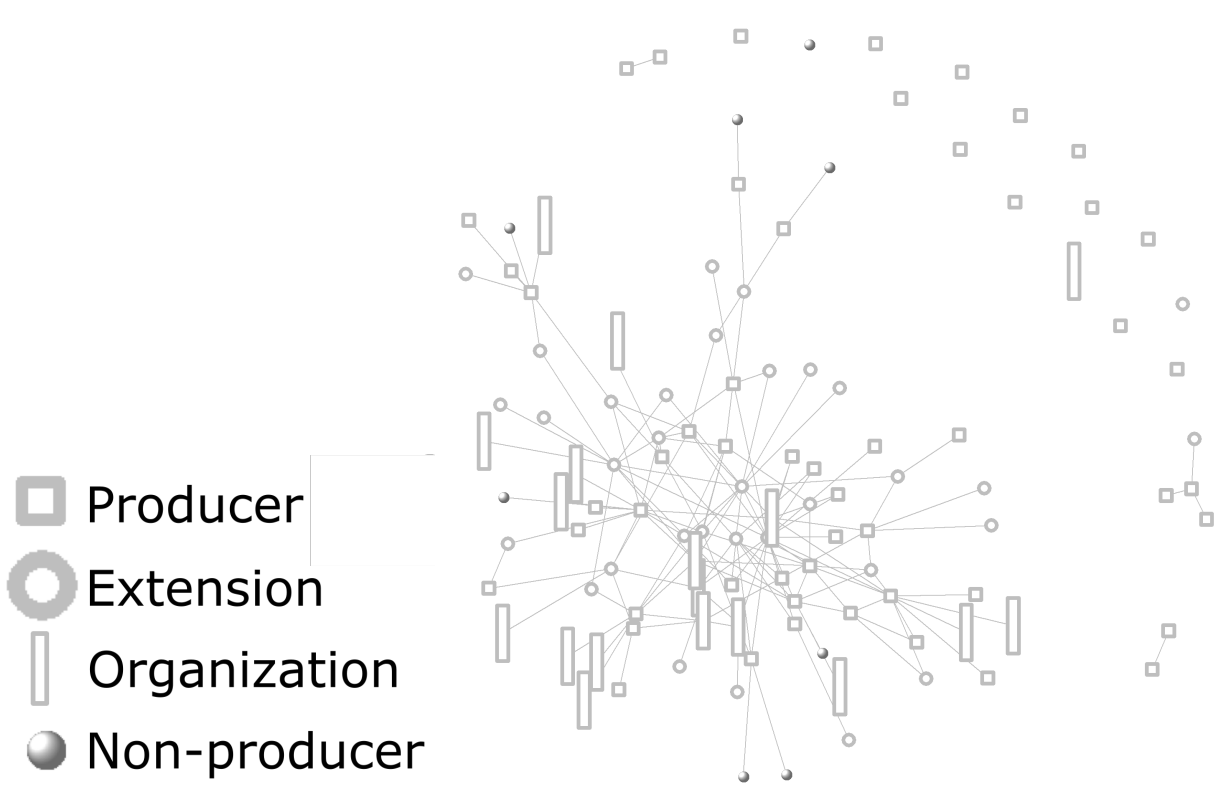

Table 2

Centrality measurements for aggregated participant groups

\begin{tabular}{lllll}
\hline Participant group & Degree & Closeness & Betweenness & Eigenvector \\
\hline Producer & 5 & .33 & 3 & 1.00 \\
Organization & 3 & .20 & 0 & 0.62 \\
Non-producer & 1 & .20 & 0 & 0.38 \\
Extension & 3 & .20 & 0 & 0.62 \\
\hline
\end{tabular}

Note. This information is most complete for producers, who were the primary respondents to the survey. 


\section{Figure 4}

Network Density of Complete and Individual Networks

Network Density

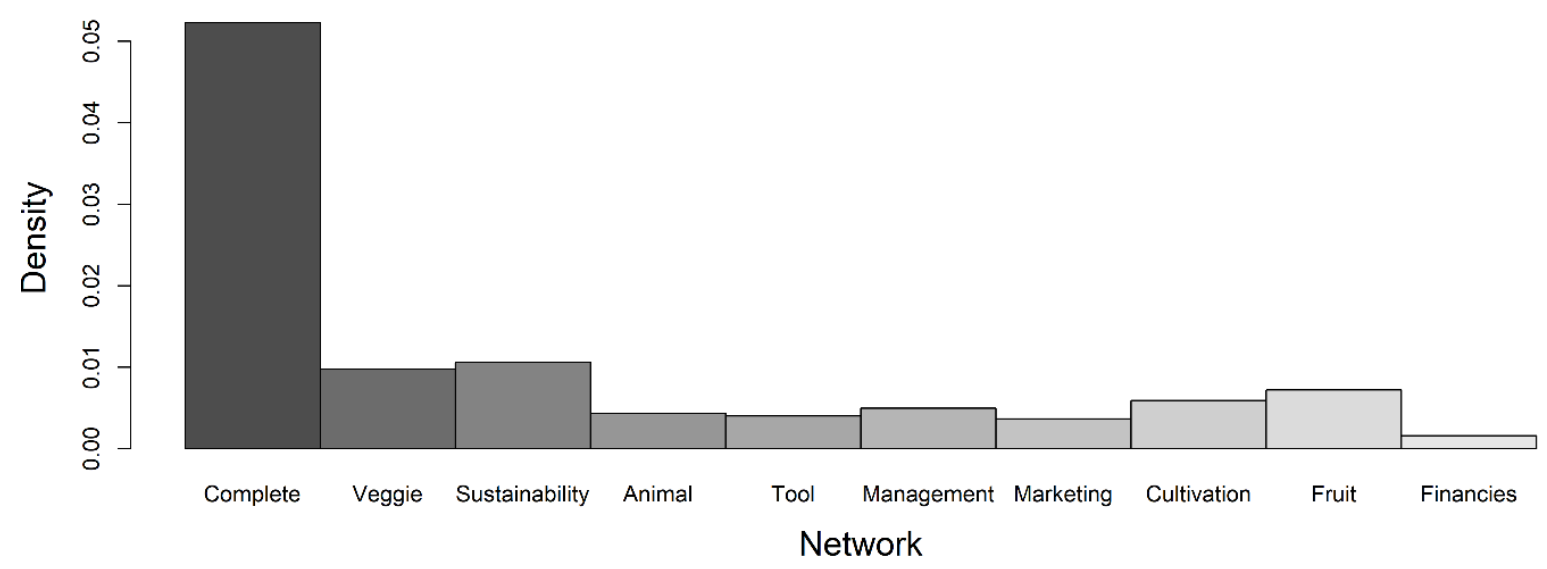

The sub-networks based on production types and information requests were significantly less integrated than the overall network, with approximately 0.5 percent of links present on average (see Figure 5).

\section{Figure 5}

Individual Sub-Networks Based on Topics of Sustainability Conversation

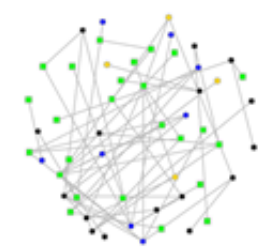

Vegetables

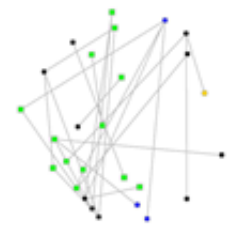

Tools

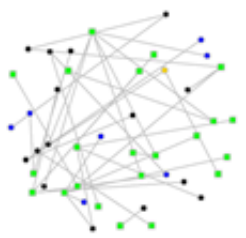

Cultivation

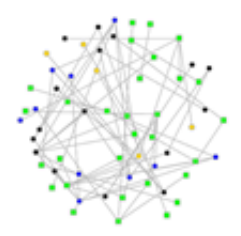

Sustainability

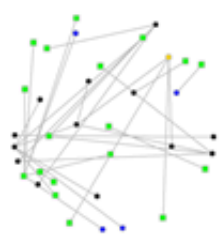

Management

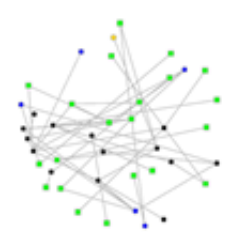

Fruits

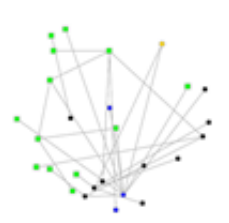

Animals

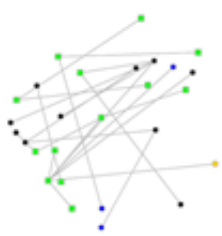

Marketing

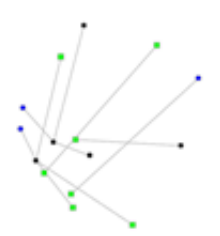

Financial 
The sub-networks were similar with edge density ranging from 0.002 to 0.01 as shown below in Table 3. Interestingly, the sustainability sub-network, regarding contacts with others about sustainability issues, appeared to have more network structure with a few important central entities. We found only weak evidence for a correlation between centrality and self-reported sustainability $(p<0.2)$ as shown in Supplemental Figure 11a-d at https://bit.ly/3q4pSNm.

\section{Table 3}

Characteristics for the Complete Network Based on Communication About at Least One Topic, and for Sub-networks Based on Communication About Individual Topics

\begin{tabular}{|c|c|c|c|c|c|c|c|c|c|c|}
\hline & 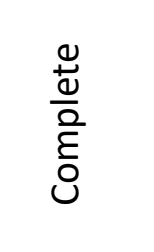 & $\begin{array}{l}\mathscr{y} \\
.00 \\
00 \\
\stackrel{0}{00}\end{array}$ & 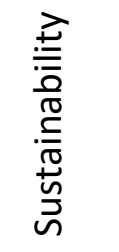 & $\frac{\bar{\sigma}}{\frac{\delta}{C}}$ & $\overline{0}$ & 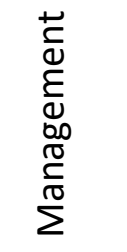 & 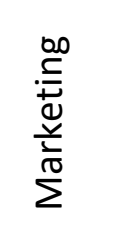 & 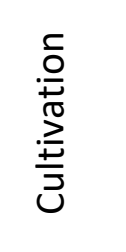 & $\frac{+1}{\frac{1}{2}}$ & 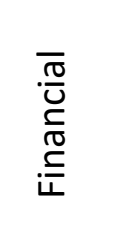 \\
\hline Edges & 151 & 61 & 66 & 27 & 25 & 31 & 23 & 37 & 45 & 10 \\
\hline Density & 0.020 & 0.010 & 0.010 & 0.004 & 0.004 & 0.005 & 0.004 & 0.010 & 0.010 & 0.002 \\
\hline $\begin{array}{l}\text { Average node } \\
\text { degree }\end{array}$ & 2.700 & 1.100 & 1.180 & 0.480 & 0.450 & 0.550 & 0.410 & 0.660 & 0.800 & 0.180 \\
\hline Diameter & 8 & 9 & 11 & 6 & 6 & 8 & 8 & 5 & 9 & 2 \\
\hline Transitivity & 0.05 & 0.05 & 0 & 0 & 0.17 & 0 & 0 & 0 & 0 & 0 \\
\hline $\begin{array}{l}\text { Average } \\
\text { betweenness }\end{array}$ & 91.72 & 17.60 & 53.00 & 6.05 & 1.27 & 9.67 & 3.76 & 1.45 & 11.30 & 0.08 \\
\hline $\begin{array}{l}\text { Average } \\
\text { closeness }\end{array}$ & 0.0002 & 0 & 0 & 0 & 0 & 0 & 0 & 0 & 0 & 0 \\
\hline
\end{tabular}

Note. Number of entities for all networks is 112 .

\section{Conclusions, Discussion, and Recommendations}

We set out to describe the communication network of potentially sustainable producers in our regional food system and its implications for regional sustainability. Our producers show some diversity in their production schemes, particularly in the ways they sell beyond directly to consumers. By and large, they manage small operations with limited annual sales, and only about half of the respondents consider their operations nearly completely sustainable. While the respondents report a variety of educational backgrounds, they are also otherwise older and of primarily White race and ethnicity. This is similar to the racial/ethnic makeup of the region overall and the age range of producers more broadly. The age of the group could mean that their knowledge could be lost as these producers retire or pass away. Our regional producers seem to be highly reliant on one-on-one interactions with other producers that they know. They do rely on Cooperative Extension, similar to other producer groups (Silvert et al., 2021) but again, may be working with particular individuals in Extension more so than the service as a 
whole. Reliance on particular personnel could add to the fragility of the network and potential knowledge loss due to retirement or job changes. Sub-networks based on particular products or topics, particularly finances, have room for strengthening.

A large percentage of isolates also indicates fragility of the network. However, the isolates are not completely disconnected from the network, as they received the survey through participation with local Extension offices, other producers or organizations, or through sales at farmer's markets. They may not be taking advantage of the resources the network has to offer particularly on sustainability, as evidenced by their failure to list communication about sustainability with the network members within the previous two years.

The reported networks for some topics and individuals appear substantially better developed than others. The analysis of a relationship between a person's role in the network and their reported farm sustainability was inconclusive, but weak evidence suggests that producers do not necessarily need to communicate with others in the region to consider themselves sustainable. Understanding and supporting people who both implement sustainable practices and have important roles in the communication networks (Cvitanovic et al., 2017; Klerkx et al., 2010) could support sustainability efforts. If people in networks tend to be linked with others similar to themselves, the resulting segregation can pose challenges for system-wide improvements to sustainability (Barnes et al., 2016). Our study helps understand the regional system, including how to better integrate those underserved by the network and necessary rates of adoption of sustainable production for regional sustainability (Garrett et al., 2018; Henry \& Vollan, 2014). Sharing these gaps in the network and resource base with service providers can enhance their support for sustainable agriculture (Christensen \& O'Sullivan, 2015).

This research faces some typical limitations. We did not have a complete picture of the network to begin with and could not define the boundaries. Producers may have received our survey but been reluctant to participate and disclose their name (Penuel et al., 2006). Finally, while we attempted to attend farmer's markets and reach people not already connected to Extension, we may have not adequately reached or sampled those producers.

Future research will involve conducting follow-up social network analysis over time as Extension and other groups continue to connect producers in the region. Re-design of our survey will also allow us to probe the directionality of the network, that is, do some producers serve primarily as purveyors of knowledge and less as recipients, or are members of the network sharing more equally? Future studies could ask in more detail about the frequency of contacts with other producers and organizations.

We highlight an existing repository of knowledge of sustainability amongst our responding producers and Extension and other local organizations. Specifically, those producers that also attended our focus groups are already implementing a number of sustainable practices and may be able to serve as resources for other producers interested in implementing these 
practices (Stofer et al., 2021). However, the network amongst these various entities with such knowledge seems highly fragile and susceptible to breakdown and knowledge loss.

\section{Acknowledgements}

We thank our producers for their time in participating in the study as well as for their contributions to our food system.

\section{References}

Adams, D. C., \& Salois, M. J. (2010). Local versus organic: A turn in consumer preferences and willingness-to-pay. Renewable Agriculture and Food Systems, 25(4), 331-341. https://doi.org/10.1017/S1742170510000219

Andersen, K. F., Buddenhagen, C., Rachkara, P., Gibson, R., Kalule, S., Phillips, D., \& Garrett, K. A. (2019). Modeling epidemics in seed systems and landscapes to guide management strategies: The case of sweet potato in Northern Uganda. Phytopathology, 109(9), 15191532. https://doi.org/10.1094/PHYTO-03-18-0072-R

Aprile, M. C., Caputo, V., \& Nayga, R. M. (2016). Consumers' preferences and attitudes toward local food products. Journal of Food Products Marketing, 22(1), 19-42. https://doi.org/10.1080/10454446.2014.949990

Barnes, M. L., Lynham, J., Kalberg, K., \& Leung, P. (2016). Social networks and environmental outcomes. Proceedings of the National Academy of Sciences, 113(23), 6466-6471. https://doi.org/10.1073/pnas.1523245113

Brass, D. J., Galaskiewicz, J., Greve, H. R., \& Tsai, W. (2004). Taking stock of networks and organizations: A multilevel perspective. Academy of Management Journal, 47(6), 795817. http://amj.aom.org/content/47/6/795.short

Buddenhagen, C. E., Hernandez Nopsa, J. F., Andersen, K. F., Andrade-Piedra, J., Forbes, G. A., Kromann, P., Thomas-Sharma, S., Useche, P., \& Garrett, K. A. (2017). Epidemic network analysis for mitigation of invasive pathogens in seed systems: Potato in Ecuador. Phytopathology, 107(10), 1209-1218. https://doi.org/10.1094/PHYTO-03-17-0108-FI

Bunge, J. (2017, October 23). Supersized family farms are gobbling up American agriculture. Wall Street Journal. https://www.wsj.com/articles/the-family-farm-bulks-up$\underline{1508781895}$

Cassman, K. G. (1999). Ecological intensification of cereal production systems: Yield potential, soil quality, and precision agriculture. Proceedings of the National Academy of Sciences, 96(11), 5952-5959. https://doi.org/10.1073/pnas.96.11.5952 
Christensen, L., \& O’Sullivan, R. (2015). Using social networking analysis to measure changes in regional food systems collaboration: A methodological framework. Journal of Agriculture, Food Systems, and Community Development, 5(3), 113-129. https://doi.org/10.5304/jafscd.2015.053.013

Cvitanovic, C., Cunningham, R., Dowd, A-M., Howden, S. M., \& van Putten, E. I. (2017). Using social network analysis to monitor and assess the effectiveness of knowledge brokers at connecting scientists and decision-makers: An Australian case study. Environmental Policy and Governance, 27(3), 256-269. https://doi.org/10.1002/eet.1752

Dillman, D. A., Smyth, J. D., \& Christian, L. M. (2009). Internet, mail, and mixed-mode surveys: The tailored design method (3rd ed). Wiley \& Sons.

Doerfert, D. L. (Ed.). (2011). National research agenda: American Association for Agricultural Education's research priorities for 2011-2015. Texas Tech University, Department of Agricultural Education and Communication. http://www.aaaeonline.org/resources/Documents/AAAE\%20National\%20Research\%20 Agenda.pdf

Dowd, A-M., Marshall, N., Fleming, A., Jakku, E., Gaillard, E., \& Howden, M. (2014). The role of networks in transforming Australian agriculture. Nature Climate Change, 4(7), 558-563. https://doi.org/10.1038/nclimate2275

Garrett, K. A., Alcalá-Briseño, R. I., Andersen, K. F., Buddenhagen, C. E., Choudhury, R. A., Fulton, J. C., Hernandez Nopsa, J. F., Poudel, R., \& Xing, Y. (2018). Network analysis: A systems framework to address grand challenges in plant pathology. Annual Review of Phytopathology, 56, 559-580. https://doi.org/10.1146/annurev-phyto-080516-035326

Giovannucci, D., Barham, E., \& Pirog, R. (2010). Defining and marketing "local" foods: Geographical indications for US products. The Journal of World Intellectual Property, 13(2), 94-120. https://doi.org/10.1111/j.1747-1796.2009.00370.x

Goetz, S. J. (2016). The roles of agricultural economists in food system research. Agricultural and Resource Economics Review, 45(3), 419-435. https://doi.org/10.1017/age.2016.8

Gold, M. V. (Ed.). (2012). Sustainable agriculture: Definitions and terms. U. S. Department of Agriculture. http://www.nal.usda.gov/afsic/pubs/terms/srb9902.shtml

Gorham, L., Rumble, J., \& Holt, J. (2015). The impact of local: Exploring availability and location on food buying decisions. Journal of Applied Communications, 99(2), 1-14. https://doi.org/10.4148/1051-0834.1046 
Griffin, T., Conrad, Z., Peters, C., Ridberg, R., \& Tyler, E. P. (2015). Regional self-reliance of the Northeast food system. Renewable Agriculture and Food Systems, 30(4), 349-363. https://doi.org/10.1017/S1742170514000027

Haythornthwaite, C. (1996). Social network analysis: An approach and technique for the study of information exchange. Library \& Information Science Research, 18(4), 323-342. https://doi.org/10.1016/S0740-8188(96)90003-1

Henry, A. D., \& Vollan, B. (2014). Networks and the challenge of sustainable development. Annual Review of Environment and Resources, 39, 583-610. https://doi.org/10.1146/annurev-environ-101813-013246

Klerkx, L., Aarts, N., \& Leeuwis, C. (2010). Adaptive management in agricultural innovation systems: The interactions between innovation networks and their environment. Agricultural Systems, 103(6), 390-400. https://doi.org/10.1016/j.agsy.2010.03.012

Kumar Chaudhary, A., \& Warner, L. A. (2015). Introduction to social network research: Application of social network analysis in Extension. University of Florida Electronic Document Information Source. http://www.edis.ifas.ufl.edu/wc196

Levy, M. A., \& Lubell, M. N. (2018). Innovation, cooperation, and the structure of three regional sustainable agriculture networks in California. Regional Environmental Change, 18(4), 1235-1246. https://doi.org/10.1007/s10113-017-1258-6

Lubell, M., Niles, M., \& Hoffman, M. (2014). Extension 3.0: Managing agricultural knowledge systems in the network age. Society \& Natural Resources, 27(10), 1089-1103. https://doi.org/10.1080/08941920.2014.933496

Marion, B. W. (1986). The organization and performance of the U.S. food system. The Organization and Performance of the U.S. Food System. https://www.cabdirect.org/cabdirect/abstract/19861837520

Martinez, S. W. (2010). Local food systems; concepts, impacts, and issues. Diane Publishing.

Meert, H., Van Huylenbroeck, G., Vernimmen, T., Bourgeois, M., \& van Hecke, E. (2005). Farm household survival strategies and diversification on marginal farms. Journal of Rural Studies, 21(1), 81-97. https://doi.org/10.1016/i.jrurstud.2004.08.007

Penuel, W. R., Sussex, W., Korbak, C., \& Hoadley, C. (2006). Investigating the potential of using social network analysis in educational evaluation. American Journal of Evaluation, 27(4), 437-451. https://doi.org/10.1177/1098214006294307

Rogers, E. M. (2003). Diffusion of innovations. Free Press. http://books.google.com/books?id=4wW5AAAAIAAJ 
Scott, J., \& Carrington, P. J. (Eds.). (2011). The SAGE handbook of social network analysis. SAGE.

Silvert, C., Diaz, J., Warner, L., \& Ochieng, W. (2021). To work alone or with peers: Examining smallholder coffee farmers' perceptions influencing collective actions. Advancements in Agricultural Development, 2(2), 1-14. https://doi.org/10.37433/aad.v2i2.95

Small Farms and Alternative Enterprises. (n.d.). Retrieved November 14, 2018, from [redacted] Sustainable Agriculture Research \& Education. (2010). What is Sustainable Agriculture? A SARE Sampler of Sustainable Practices. North Central SARE. https://smallfarm.ifas.ufl.edu/

Stofer, K. A., Santos-Santiago, D., Keown, H., \& Prizzia, A. (2021). Producers Have Expanded Definitions of Sustainability. Sustainability. [Manuscript in Preparation].

Tilman, D., Balzer, C., Hill, J., \& Befort, B. L. (2011). Global food demand and the sustainable intensification of agriculture. Proceedings of the National Academy of Sciences, 108(50), 20260-20264. https://doi.org/10.1073/pnas.1116437108

Tilman, D., Cassman, K. G., Matson, P. A., Naylor, R., \& Polasky, S. (2002). Agricultural sustainability and intensive production practices. Nature, 418, 671-677. https://doi.org/10.1038/nature01014

United States Department of Agriculture Economic Research Service. (2018, August 30). Farming and Farm Income. https://www.ers.usda.gov/data-products/ag-and-foodstatistics-charting-the-essentials/farming-and-farm-income/

Xu, Q., Huet, S., Poix, C., Boisdon, I., \& Deffuant, G. (2018). Why do farmers not convert to organic farming? Modeling conversion to organic farming as a major change. Natural Resource Modeling, 31(3), e12171. https://doi.org/10.1111/nrm.12171

Zack, M. H. (2000). Researching organizational systems using social network analysis. 33rd Annual Hawaii International Conference on System Sciences, 1, 1-7. https://doi.org/10.1109/HICSS.2000.926933

(C) 2022 by authors. This article is an open access article distributed under the terms and conditions of the Creative Commons Attribution license (http://creativecommons.org/licenses/by/4.0/). 